\title{
CORRECTION OF SCOLIOSIS IN CHILDREN WITH CONGENITAL HEART DEFECTS
}

\author{
CORREÇÃO DA ESCOLIOSE EM CRIANÇAS COM DEFEITOS CARDÍACOS CONGÊNITOS \\ CORRECCIÓN DE LA ESCOLIOSIS EN NIÑOS CON DEFECTOS CARDIACOS CONGÉNITOS
}

Stepan Kudryakov, ${ }^{1}$ llya Shavyrin, ${ }^{1}$ Sergey Kolesov, ${ }^{2}$ Konstantin Ukolov, ${ }^{2}$ Dmitriy Gorbatyuk, ${ }^{2}$ Andrey Panteleyev, ${ }^{2}$ Vladimir Aizenberg ${ }^{3}$

1. Scientific and Practical Center for Medical Care for Children with Developmental Defects of the Craniofacial Region and Congenital Diseases of the Nervous System, Group of vertebrology and orthopedics, Moscow, Russia.

2. N.N. Priorov Central Institute of Traumatology and Orthopedics, Department of Spine Pathology, Moscow, Russia.

3. N.I. Pirogov Russian National Research Medical University, Moscow, Russia.

\begin{abstract}
Objective: The purpose of this study was to evaluate the results of treatment in patients with deformities of the spine and congenital heart defects Methods: Eighty-seven children aged 10 to 18 years old (27 males and 60 females) were treated surgically due to scoliosis. Results: The minimum angle of the curvature arc was $68^{\circ}$. The deformity parameters were evaluated on the basis of the spine x-ray. In patients with combined and rigid forms of scoliosis, correction was performed using dorsal segmental instrumentation. Where there was rigid deformity and it was not possible to perform a front release according to the somatic indications, a one-stage dorsal correction was performed in conditions of halo traction in combination with SPO or Ponte osteotomy. In patients with moderate impairment of blood circulation in the presence of rigid curvature of the main arch, two-stage surgery was performed, with ventral release at the apex of deformation, followed by halo traction. As a second stage, dorsal correction and stabilization of the spine was performed. In the operated patients, the mean correction with dorsal instrumentation was $64.2 \%$. An average of 12 vertebrae were included in fusion. The degree of apical vertebral body derotation was found to be up to $30 \%$ of the initial rotation. With the use of hybrid and hook systems, the average degree of derotation was $18 \%$. According to the physical examination within one year, the parameters of the function of external respiration and bronchial permeability increased significantly, from $10 \%$ to $30 \%$, which indicates the functional nature of changes in cardiorespiratory disorders. Level of evidence IV, Case series.
\end{abstract}

Keywords: Osteotomy; Spinal injuries; Respiration; Pediatrics.

\section{RESUMO}

Objetivo: A finalidade deste estudo foi avaliar os resultados do tratamento em pacientes com deformidades da coluna vertebral e defeitos cardíacos congênitos. Métodos: Oitenta e sete crianças com idades entre 10 e 18 anos (27 meninos e 60 meninas) tiveram escoliose cirurgicamente tratada. Resultados: O ângulo mínimo do arco de curvatura foi $68^{\circ}$. Os parâmetros de deformidade foram avaliados com base na radiografia da coluna. Nos pacientes com formas combinadas e rígidas de escoliose, a correção foi realizada com instrumentação dorsal segmentar. Nas deformidades rígidas e quando não foi possível realizar a liberação ventral de acordo com as indicações somáticas, realizou-se a correção dorsal em um estágio, em condições de tração com halo combinada com osteotomia de Smith-Petersen (SPO) ou de Ponte. Em pacientes com comprometimento moderado da circulação sanguínea e cunvatura rígida do arco principal, usou-se a cirurgia em dois estágios, com liberação ventral no ápice da deformação, seguida por tração com halo. No segundo estágio, realizou-se a correção e estabilização dorsal da coluna. Nos pacientes operados, a média de correção com instrumentação dorsal foi 64,2\%. A fusão incluiu uma média de 12 vértebras. O grau de desrotação apical do corpo vertebral encontrado foi de até 30\% da rotação inicial. Com o uso de sistemas híbridos e de gancho, o grau médio de desrotação foi 18\%. Conclusão: De acordo com o exame clínico do primeiro ano, os parâmetros da função de respiração externa e permeabilidade bronquial tiveram melhora significante, de $10 \%$ para $30 \%$, o que indica a natureza funcional das mudanças dos distúrbios cardiorrespiratórios. Nível de Evidência IV, Série de casos.

Descritores: Osteotomia; Traumatismos da coluna vertebral; Respiração; Pediatria.

\section{RESUMEN}

Objetivo: La finalidad de este estudio fue evaluar los resultados del tratamiento en pacientes con deformidades de la columna vertebral y defectos cardíacos congénitos. Métodos: Ochenta y siete niños con edades entre 10 y 18 años (27 niños y 60 niñas) tuvieron escoliosis quirúrgicamente tratada. Resultados: El ángulo mínimo del arco de curvatura fue $68^{\circ}$. Los parámetros de deformidad fueron evaluados con base en la radiografía de la columna. En los pacientes con formas combinadas y rígidas de escoliosis, la corrección fue realizada con instrumentación dorsal segmentaria. En las deformidades rígidas y cuando no fue posible realizar la liberación ventral de acuerdo con las indicaciones somáticas, se realizó la corrección dorsal en una etapa, en condiciones de tracción con halo combinada con osteotomía de Smith-Petersen (SPO) o de Ponte. En pacientes con compromiso moderado de la circulación sanguínea y curvatura rígida del arco principal, se usó la cirugía en dos etapas, con liberación ventral en el ápice de la deformación, seguida por tracción con halo. En la segunda etapa, se realizó la corrección y estabilización dorsal de la columna. En los pacientes operados, el promedio de corrección con instrumentación dorsal fue 64,2\%. La fusión incluyó un promedio de 12 vértebras. El grado de desrotación apical del cuerpo vertebral encontrado fue de hasta $30 \%$ de la rotación inicial. Con el uso de sistemas híbridos y de gancho, el grado promedio de desrotación fue 18\%. Conclusión: De acuerdo con el examen clínico del primer año, los parámetros de la función de respiración externa y permeabilidad bronquial tuvieron mejora significativa, de $10 \%$ para $30 \%$, lo que indica la naturaleza funcional de los cambios de los disturbios cardiorrespiratorios. Nivel de Evidencia IV, Serie de casos.

Descriptores: Osteotomía; Traumatismos vertebrales; Respiración; Pediatría.

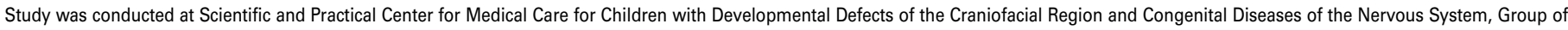

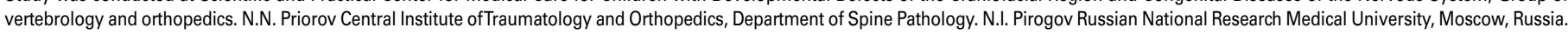
Correspondence: Stepan Kudryakov. 38 Aviatorov St, Moscow, Russia. 119620. ventral@ya.ru 


\section{INTRODUCTION}

In modern practice, the number of patients presenting with scoliosis and congenital heart disease has increased. According to the literature, scoliosis is present in $19.5 \%$ of patients with mitral valve prolapse. ${ }^{1}$ Among patients with coarctation of the aorta and an open arterial duct, deformity of the spine is revealed in $16.6 \%$ of cases. ${ }^{2,3}$ The prevalence of secondary scoliosis after thoracotomy is significantly higher than after minimally invasive and non-surgical treatment methods, as well as among the general population. 2,3 Thoracotomy in patients with coarctation of the aorta and open arterial duct leads to the development of scoliosis in $36.6 \%$ of cases. ${ }^{4}$ It is known that among patients submitted to Fontaine's surgery, scoliosis is found in $9.8 \%$ of children over the age of 5 years. A right-sided thoracic arch is found in $63.2 \%$ of cases, left-sided thoracic in $21.1 \%$, and high thoracic arch in $15.8 \%$. The risk of scoliosis increases to $27 \%$ with each year of life. Therefore, children who have undergone heart surgery need a follow-up examination, conducted by specialists, for timely detection of the spine deformity. ${ }^{5}$

In patients with idiopathic scoliosis who do not receive timely treatment, cardiopulmonary insufficiency may develop due to right ventricular overload. ${ }^{6,7}$ This demonstrates the importance of timely orthopedic care for this category of patients. The high risk involved in intraoperative and early postoperative complications is often the reason for not performing surgical correction of the spinal deformity. The aim of the work: To evaluate the results of treatment in patients with spinal deformities and heart defects.

\section{METHODS}

Eighty-seven children aged 10 to 18 years (mean age 12.4 years) who had been surgically treated for scoliosis were in follow-up at the SPC of medical care for children of the Moscow Department of Health and the Federal Governmental Institution CITO, named after N.N. Priorov. There were 27 males and 60 females. The minimum angle of the curvature arc was $68^{\circ}$; the maximum was $94^{\circ}$. Congenital scoliosis was found in of the 30 children; idiopathic in 52 , secondary (scoliosis after heart surgery) in 5. Patients underwent dorsal correction of the spinal deformity. For the fixation, we used the hook system $(n=10)$, helical system $(n=35)$ and hybrid fixation system $(n=42)$ (sublaminar locks - hooks, croches + screws). The ring halo was fitted in 60 patients, with single-stage dorsal correction in 32, two-stage correction in 42, and Smith-Peterson (SPO or Ponte) osteotomy in 13 patients.

Blood loss was assessed using a gravimetric method, and in the case of intraoperative reinfusion of wound blood, the "Cell Saver" readings were taken into account. Eighty out of the 87 children had cardiovascular failure (circulatory deficiency 0-1st degree). Among these children, the following heart defects were identified: the only ventricle (three-chambered heart) in 1 case, open arterial duct in 2 cases, defects of the interatrial septum in 4 cases, interventricular septum defects in 4 cases, mitral valve stenosis in 1 case, valvular heart disease in 27 cases, mitral valve prolapse in 14 cases, mitral valve insufficiency in 3 cases, mitral valve deficiency in combination with tricuspid insufficiency in 5 cases, with aortic insufficiency in 3 cases, and with pulmonary valve stenosis in 2 cases. Cardiomyopathy was diagnosed in 5 children. In addition, we observed 5 patients who had undergone heart surgery: 1 for pulmonary artery stenosis, 1 for open arterial duct, 2 for interventricular septum defect, 1after radical correction of the double ventricular vascular withdrawal from the right ventricle, plasty of the interventricular defect septa, and elimination of pulmonary artery stenosis. The surgical was performed on patients with grade IV scoliosis (according to Chaklin's classification) in the presence of hemodynamically compensated defects of the cardiovascular system.

The severity of the disease was assessed, taking into account the degree of curvature of the spine and the patient's somatic status. The deformity parameters were evaluated on the basis of the spine $x$-ray. To determine the mobility of the deformity, functional tests - bending tests and a traction test - were carried out. Mobile deformities were defined as those with a correction value in the functional radiographs of $35 \%$ and above the initial angle, and rigid deformities were defined as those with a correction value less than $35 \%$. Mobile deformities were recorded in 48 children, rigid ones in 39. Thoracic scoliosis was found in 23 cases, lumbar scoliosis in 17, and combined scoliosis in 47. Respiration function was evaluated with spirography, and electrocardiography and echocardiography were also performed. Patients were seen by a cardiologist. The operational anesthesia risk was evaluated based on the American Association of Anesthetists (ASA) Physical Status Classification of $1963^{8}$ and the Russian Moscow Scientific Society of Anaesthesiologists and Reanimatologists - MSSAR classification (rus. MHOAP) (1989). The first classification determines the patient's initial physical status, while the second also takes into account the nature of the surgical intervention. In patients with combined and rigid forms of scoliosis, the correction was performed using dorsal segmental instrumentation. In cases of rigid deformity and inability to perform a front release according to the somatic indications, a one-stage dorsal correction was performed in conditions of halo traction in combination with SPO or Ponte osteotomy. After applying the halo ring, dorsal access was established with transpedicular screws, then resection of the spinous processes was performed on the segments selected for posterior osteotomy. With the help of Kerrison's pistol clippers, the yellow ligament and arches were resected on the right and left sides. To stem the bleeding from the epidural vessels and damaged bone, a collagen haemostatic sponge and wax were used. If there was a high risk of complications, dorsal stabilization of the spine with moderate correction was performed. In order to reduce the risks of intraoperative and postoperative complications and shorten the surgery time, a segmental dorsal hook instrumentation was used in combination with the intraoperative halotraction. In patients with moderate impairment of blood circulation in the presence of rigid curvature of the main arch, two-stage operative treatment was performed. The first stage was performed by thoracotomy, ventral release at the apex of deformation, and assembly of the halo ring. Dorsal correction was performed as a second stage, after wound healing and recovery, as well as stabilization of the spine using segmental instruments of screw, hook and hybrid equipment. The study was approved by the N.N. Priorov Central Institute of Traumatology and Orthopedics (No. 579253). All participants signed an Informed Consent Form prior to enrolling in the study. All authors declare no potential conflict of interest related to this article.

\section{Anesthesia principles in the surgical treatment of scoliosis in children with heart defects.}

Principles of anesthesia for scoliosis surgery in children are associated with the vastness of the operating field and high traumatism, significant blood loss, and the presence of concomitant pathology in the form of circulatory disorders and respiratory failure. The first two factors are related to the surgical side of the problem, but the anesthesiologist should consider them when in the choice of anesthetic strategy. Prevention of complications associated with concomitant pathology is entirely the prerogative of the anesthesiologist. Operational risk on the ASA scale in the majority (93.1\%) of our patients was third degree. First to third-degree respiratory failure was noted in all (87) patients: restrictive type in 47 patients, obstructive in 14 , and mixed in 26 . Therefore, to prevent respiratory complications, it was important to ensure that the patients were breathing spontaneously after surgery, and in a state of complete decurarization. Also adequate analgesia of the operating wound was required; this was achieved due to epidural analgesia with $0.1-2.2 \%$ naropin solution with additional use of perfalgan and NSAID preparations (non-steroidal anti-inflammatory drugs) when monitoring blood gases. Adequate analgesia enables the patient to perform breathing exercises and provokes a cough. It ensures the active position of the child in bed, and reduces postoperative nausea and vomiting.

Transthoracic release of the intervertebral structures and dorsal correction of scoliosis was performed under general multicomponent anesthesia, with sevoflurane as the main anesthetic, and bolus 
injection of fentanyl against a background of artificial ventilation and postoperative parenteral analgesia with promedol in combination with NSAIDs. In 45 children, dorsal correction of scoliosis involved lumbar epidural analgesia with morphine and anesthesia-assisted sevoflurane in subanesthetic doses, with artificial ventilation. Postoperative analgesia was provided by epidural analgesia with ropivacaine in combination with NSAIDs.

\section{Clinical case}

A 12-year-old patient was admitted to hospital with combined IV grade scoliosis of the thoracolumbar spine. Anamnestic data: child from the 3rd pregnancy, which took place physiologically, the birth is $3^{\text {rd }}$, on time. Birth weight was 3100 grams, height $53 \mathrm{~cm}$. The diagnosis was established in the first year of life: Congenital heart disease: a double vascular withdrawal from the right ventricle, a pseudorhtalic interventricular septum defect (distension of the aorta and pulmonary trunk from the right ventricle of the heart is a "double divergence" from the right ventricle, a complex congenital malformation in which both main arteries move away from the right ventricle, there is a defect of the interventricular septum.) The disease is relatively rare, accounting for just $1 \%$ of all congenital heart defects. In 2002, the child underwent surgical treatment at the Bakulev National Medical Research Center of Cardiovascular Surgery, where he underwent radical correction of the defect of double separation of the main vessels from the right ventricle. Deformation of the spine was detected at an early age, progressing from 5 years. The child was observed at home, by an orthopedist. Conservative treatment with courses was conducted, without positive dynamics. Surgery was recommended. Orthopedic status at admission to the hospital: the child received no additional assistance, the trunk is asymmetrical, the head is shifted to the left of the median line, the thorax is deformed, with a gently curving rib hump on the right, the right shoulder-line is $7 \mathrm{~cm}$ above the left, the nipples are equidistant from the midline, on one level, the triangles of the waist are asymmetric, the navel is in the midline, skewing of the pelvis is not present when viewed from the side, cervical lordosis is increased, thoracic kyphosis is increased, lumbar lordosis is enlarged. When viewed from behind: the spine axis is dislocated. Scoliotic curvature of the thoracic, lumbar spine is present. The angles of the scapulae are asymmetric. The intergluteal fold is shifted to the left of the plumb line by $3 \mathrm{~cm}$ (Figure 1A, B, B). The lower limbs are equal in length. Range of movement in the large and small joints of the upper and lower extremities is complete and unrestricted. The arches of the feet are formed by age.

On the radiographs, a scoliotic right-sided arch is visualized at Th1-Th11 level with a 95 Cobb angle. Left-sided lumbar arch at level Th12-L5 with Cobb angle of $81^{\circ}$ (Figure $2 \mathrm{~A}, \mathrm{~B}$ ). When the traction test is performed, the correction is less than $35 \%$. With magnetic resonance imaging, the spinal cord pathology is not revealed. ECG: sinus rhythm, heart rate 107 per 1 minute, normal position of the electrical axis of the heart. The child was consulted by a

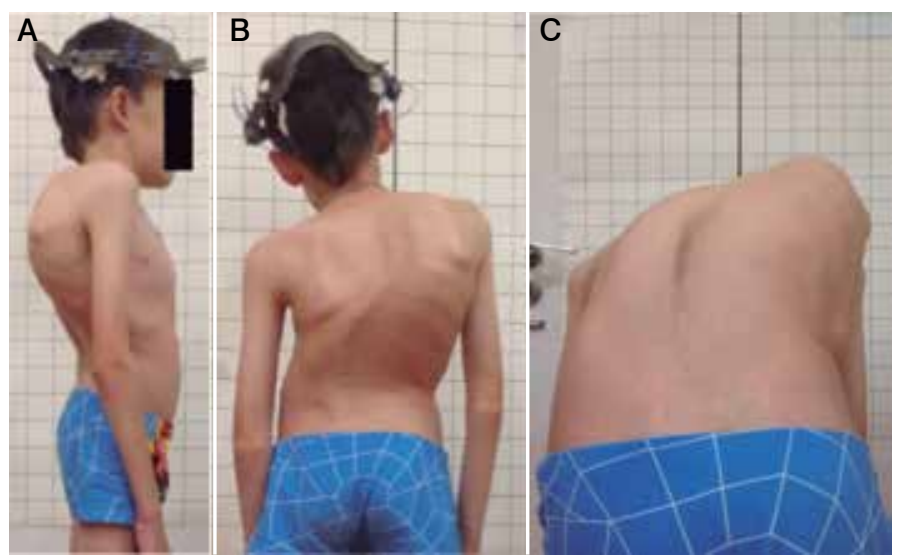

Figure 1. Patient's appearance before surgery.
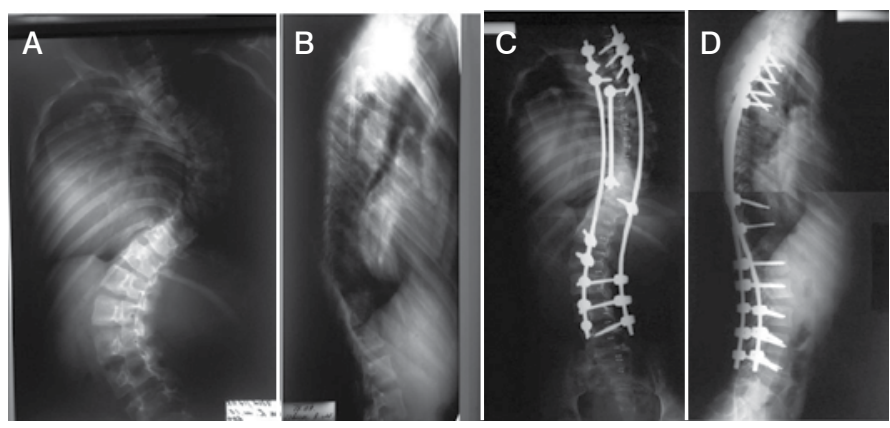

Figure 2. Patient's $X$-rays before $(A, B)$ and after $(C, D)$ surgery.

cardiologist at the Bakulev centre. Conclusion: congenital heart disease: a double vascular leakage from the right ventricle, and interventricular septum defect. The condition after the operation of radical correction of double vascular withdrawal from the right ventricle, plastic defect of the interventricular septum, and elimination of stenosis of the pulmonary artery (2002). There are no contraindications for prompt correction of scoliosis. In consultation with a geneticist, a hereditary pathology was established: frontal metaphyseal dysplasia with a recessive X-linked type of inheritance. (OMIM: 305620 Skeletal abnormalities are described: scoliosis, funnel-shaped and keellike deformity of the chest, X-ray examination revealed diffuse hyperostosis of the skull, especially in the frontal part). The patient underwent two-stage surgical treatment. The first step was the application of the halo ring. In order to mobilize the spine deformity, a halo brace was performed in the orthopedic chair. The somatic state was stable. There were no hemodynamic disturbances from the cardiovascular system. The second stage was the surgery itself: Dorsal correction of scoliosis, and stabilization of the spine by instrumentation at levels Th1-L5. Concerning the "rough" deformation, the patient underwent an indirect derotation maneuver, and dorsal correction of the scoliosis. The operation lasted 2 hours 35 minutes, the anesthesia lasted 3 hours 40 minutes. The patient spent the first 24 hours after the operation in the intensive care unit. He was transferred to the police department on the second day after the operation. In the first week of the postoperative period, complaints of a periodic feeling of heat, and a rapid heart rate were noted. In the control ECG: complete blockade of the right leg of the His bundle. Overload of RV (right ventriculus) + LV (left ventriculus). Signs of myocardial hypoxia: QT lengthening of $0.5 \mathrm{sec}$. The child was seen by a cardiologist. Conclusion: The condition after the surgical radical correction of double vascular withdrawal from the right ventricle, plastic defect of the interventricular septum, elimination of pulmonary artery stenosis (2002). Congenital Heart Disease (pulmonary artery stenosis). Moderate insufficiency of the valve of the pulmonary artery and aortic valve. Circulative insufficiency, grade 0 . Dysfunction of the sinus node (vagus dependent). Distortion of intraventricular conduction - a complete blockade of the right leg of the bundle. With medical treatment provided (anaprilin, riboksin + panangin, elkar 30\%), as well as adequate anesthesia in the postoperative period, stabilization of the patient's condition was noted. The postoperative wound healed primary. The patient was discharged to outpatient treatment on the 14th day in a satisfactory condition. A satisfactory correction of the deformity of the spine was achieved, the residual scoliotic right-hand arc was visualized on the X-ray after the operation at level Th1-Th11 level with Cobb angle of $58^{\circ}$. Left-sided lumbar arch at level Th12-L5 with Cobb angle of $36^{\circ}$ (Figure $2 \mathrm{~B}, \mathrm{D}$ ). Proper frontal and sagittal balance of the spine was achieved (Figure $3 \mathrm{~A}, \mathrm{~B}, \mathrm{C}$ ).

\section{RESULTS}

The results of correction of scoliosis in patients with congenital cardiovascular system defects receiving surgical care were evaluated, taking into account the values of the initial and postoperative 


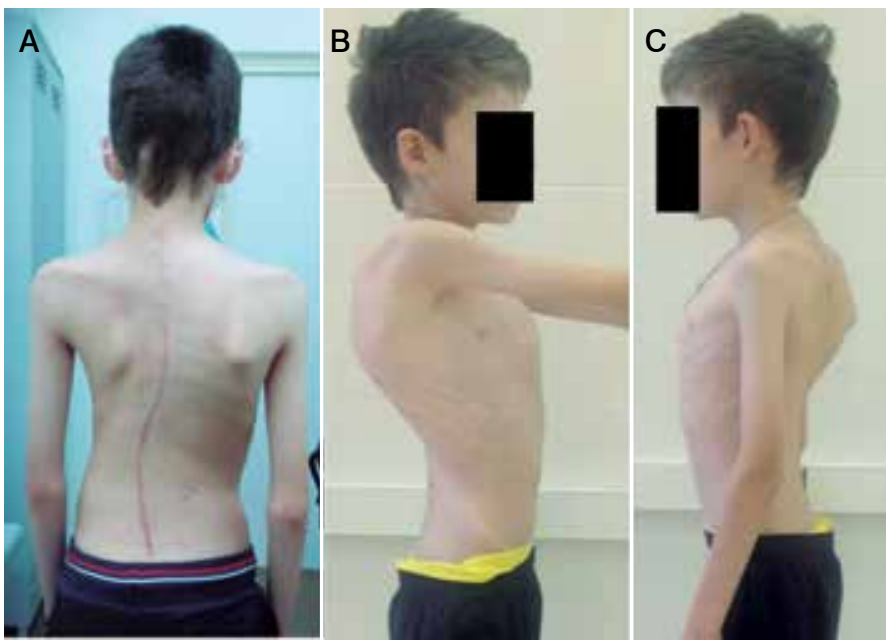

Figure 3. Patient's appearance after surgery.

deformity, the main and compensatory arches, the length of fixation, the duration of the operative intervention, and the volume of blood loss. Long-term results of treatment were monitored, changes in the rotation of vertebral bodies were performed, according to computed tomography (Table 1).

In the operated patients, the mean correction with dorsal instrumentation was $64.2 \%$. The minimum Cobb angle of curvature arc was $62^{\circ}$, the maximum $94^{\circ}$. The average initial Cobb angle of the scoliotic deformation was $78.5^{\circ}$. After the operation, the value of the main arc was $34.2^{\circ}$ (from 30 to $42^{\circ}$ ). The angle of the kyphosis of the thoracic spine was $46.5^{\circ}$. The kyphosis angle of the thoracic spine after surgical treatment $34.4^{\circ}$. An average of 12 vertebrae (from 11 to 15 vertebrae) are included in the spondylodesis. The derotation effect with screw systems was observed. The mean initial rotation of the apical vertebra was $43.3^{\circ}$ after surgery $30.2^{\circ}$. The degree of apical vertebral body derotation was found to be up to $30 \%$ of the initial rotation. With the use of hybrid and hook systems, the average initial rotation of the apical vertebra was $21.2^{\circ}$ and after surgery, $18.2^{\circ}$. The degree of derotation achieved was $18 \%$. Ventral access was used to release the intervertebral structures in patients with hemodynamically insignificant heart defects. This was performed in 40 patients. The main method of mobilization of the spine was halo traction in the orthopedic chair for 10-15 days. With rigid deformities, dorsal mobilizing osteotomy (SPO or Ponte) was also used. In patients with a high risk of complications, one-stage dorsal correction was performed.

Assessment of respiratory function established the presence of first to third degree respiratory failure in all our patients. In the first month of the postoperative period, tachycardia was noted, as well as a marked decrease in the parameters of the function of external respiration (in particular, a decrease in lung capacity of 10-15\%), which is associated with pain. One year after the operation, the examinations confirm an increase in lung capacity to $30 \%$, which indicates adaptation of the cardiorespiratory system to the conditions for correcting scoliosis, with normalization of the somatic parameters (Table 2).

The duration of the operative intervention was 210 minutes. With dorsal correction, blood loss was $930 \mathrm{ml}$ (from 530 to $2150 \mathrm{ml}$ ); with ventral access it was $264 \mathrm{ml}(165$ to $560 \mathrm{ml})$. During the operations with ventral access and in 42 children with dorsal correction of scoliosis, operated under general anesthesia, hemodynamics was accompanied by sharp fluctuations in mean arterial pressure from 60 to $100 \mathrm{~mm}$ of mercury in the operation stages, tachycardia, and unstable hemodynamics. At the time of traction of the spine during dorsal correction of scoliosis against a background of a decrease in mean arterial pressure to $50 \mathrm{mmHg}$ and a reduction in the perfusion of the spinal cord, conditions arose for myelo-ischemia, which in one child, led to the development of lower paraplegia and required emergency dismantling off the metal structure, leading to regression of the neurologic symptoms within 10 days and the repeated dorsal stabilization of the spine with a measured correction. The use of regional methods in anesthetic care in 45 children with dorsal correction of scoliosis enabled fluctuations in blood pressure to be reduced to within $10 \%$ during the operation. Inotropic dopamine support at a dose of $2.5 \mu \mathrm{g} / \mathrm{kg} / \mathrm{h}$ was performed in 48 children, and at a dose of $5 \mu \mathrm{g} / \mathrm{kg} / \mathrm{h}$ or higher in 3 children. In one child with a threechambered heart (single ventricle), inotropic support was carried out with cardiotonic dobutamine at a dose of $5-7.5 \mu \mathrm{g} / \mathrm{kg} / \mathrm{h}$ during the operation and for the first 2 days after the operation. Extended prolonged ventilation for 1 day was performed in 2 children after dorsal correction of scoliosis. After transthoracic access, 2 children underwent mechanical ventilation for 2 days. After transthoracic access, development of unilateral hydrothorax (jet effusion) was noted in 14 patients up to 8 days, and puncture was required to remove exudate. The average length of stay in the intensive care unit was 2 days (from 1 to 9 days).

Table 2. Respiratory parameters of the operated patients.

\begin{tabular}{c|c|c|c}
\hline Respiratory parameters & Preoperative & $\begin{array}{c}\text { 1 month } \\
\text { postoperative }\end{array}$ & $\begin{array}{c}\mathbf{1 2} \text { months } \\
\text { postoperative }\end{array}$ \\
\hline Lung capacity \% & 56.0 & 51.0 & 71.0 \\
\hline PO2 at inhale & 0.80 & 0.73 & 0.98 \\
\hline PO2 at exhale & 0.49 & 0.43 & 0.90 \\
\hline Functional lung capacity & 66.0 & 61.8 & 81.4 \\
\hline $\begin{array}{c}\text { Forced exhale volume } \\
\text { per 1 min./lung } \\
\text { capacity \% }\end{array}$ & 90.0 & 86.0 & 102.6 \\
\hline
\end{tabular}

Table 1. Overall results.

\begin{tabular}{c|c|c|c|c}
\hline & $\begin{array}{c}\text { Two-stage treatment (rigid } \\
\text { scoliosis) }\end{array}$ & $\begin{array}{c}\text { One-stage correction (mobile } \\
\text { scoliotic deformity) }\end{array}$ & $\begin{array}{c}\text { One-stage treatment. Rigid } \\
\text { scoliotic deformity; dorsal } \\
\text { correction + (mobilizing) } \\
\text { Smith-Petersen osteotomy }\end{array}$ & $\begin{array}{c}\text { One stage treatment, rigid } \\
\text { scoliotic deformity. Patients } \\
\text { at high risk of cardiovascular } \\
\text { complications }\end{array}$ \\
\hline Number of patients & 40 & 20 & 13 & 14 \\
\hline Pre-op Cobb angle & 93.9 & 67.5 & 76.2 & 63.3 \\
\hline Post-op Cobb angle & 40.1 & 28.2 & 26.3 & 32.2 \\
\hline Thoracic kyphosis & & & & \\
\hline Pre-op Cobb angle & 64.2 & 35.1 & 38.5 & 37.6 \\
\hline Post-op Cobb angle & 45.4 & 29.2 & & 34.3 \\
\hline $\begin{array}{c}\text { Apical vertebra } \\
\text { derotation }\end{array}$ & & & & \\
\hline Pre-op value, in degrees & 43.3 & 20.3 & 28.3 & \\
\hline $\begin{array}{c}\text { Post-op value, in } \\
\text { degrees }\end{array}$ & 30.1 & 13.8 & 12.2 & 21.2 \\
\hline
\end{tabular}




\section{DISCUSSION}

Surgical correction of scoliosis is associated with high traumatism, due to the vastness of the operating field and the significant blood loss involved. Patients with non-operated congenital heart defects and those who have undergone open and closed heart surgery often have normal hemodynamics or residual disturbances that affect the planning and conduct of surgical correction of scoliosis. Ventral access in mobilizing scoliosis was used by our team in patients with congenital heart defects but without signs of hemodynamic disturbances. Due to the presence of additional cardiovascular risks in the child, ventral access could not be performed. As an alternative to the ventral release, we used a halo ring attachment. Halo traction was performed in the orthopedic chair for $10-15$ days. This adapts the patient to the correction conditions and creates passive mobilization of the deformity by stretching the ligament apparatus. When performing a dorsal correction of scoliosis, we used mobilization in the form of a Smith-Peterson osteotomy (SPO or Ponte). Combination of the above surgical techniques with the use of a polysegment screw and combined instruments provided adequate correction of deformation and reliable stabilization of the spinal column. Preventing complications associated with concomitant pathology is the prerogative of the anesthesiologist. First to third-degree respiratory failure was present in all our patients; therefore, to prevent respiratory complications, patients should be transferred to spontaneous breathing after surgery in a state of complete decurarization, and with adequate analgesia due to epidural analgesia in conjunction with NSAIDs when monitoring blood gases. Due to the reduced need for relaxants, systemic narcotic analgesics and anesthetics, inclusion of regional methods of analgesia in anesthesia in the surgical correction of scoliosis in children with heart defects helps prevent cardiovascular and respiratory complications, and significantly increases the efficiency of postoperative analgesia, contributing to earlier rehabilitation. According to the physical examination within one year, the parameters for external respiratory function and bronchial permeability were significantly increased, with an increase in rates from $10 \%$ to $30 \%$, which indicates the functional nature of changes in cardiorespiratory disorders. Operative correction of scoliosis prevents the somatic changes that develop as a result of scoliosis, the formation of pulmonary hypertension and kyphoscoliotic heart in the adulthood.

\section{CONCLUSIONS}

The results and extent of surgical correction in patients with congenital heart disease are comparable with those for idiopathic scoliosis. The use of ventral access in patients with heart defects increases the risk of developing respiratory and cardiovascular insufficiency in the postoperative period. An alternative to ventral release when mobilizing rigid spinal deformities in patients with congenital heart defects is the use of halo-traction and dorsal osteotomy according to SPO or Ponte. The inclusion of regional methods of analgesia in anesthesia in the surgical correction of scoliosis in children with heart defects by reducing the need for relaxants, systemic narcotic analgesics and anesthetics helps prevent cardiovascular and respiratory complications, and significantly increases the efficiency of postoperative analgesia, which contributes to earlier rehabilitation. When planning an operation, factors of a decrease in intraoperative blood loss should be taken into account. In the case of severe circulatory disturbances in patients with scoliosis, it is necessary to involve a cardioanestesiologist with experience in general anesthesia and cardiosurgery.

All authors declare no potential conflict of interest related to this article.

CONTRIBUTION OF THE AUTHORS: Each author made significant individual contributions to this manuscript. SK (Orcid) and IS (Orcid) were the main contributors to the drafting of the article. SK (Orcid), KU (Orcid) and VA (Orcid) supervised and were the main contributors to the surgical treatment, anesthesiological coverage and data evaluation. AP (Orcid), DG (Orcid) provided extensive help in the material processing, editing of the text, literature search, and review of manuscript. . ${ }^{\star}$ RRCID (Open Researcher and Contributor ID).

\section{REFERENCES}

1. American Society of Anesthesiologists. New classification or physical status. Anestesiology. 1963;24(1):111.

2. Avtandilov AG, Vetrile ST, Enaldieva RV, Nemanova DI, Kuleshov AA. Noninvasive preoperative assessment of the cardio-respiratory system in adolescents with severe chest scoliosis. Chirurgia pozvonochnika. 2004;2:45-8.

3. Nemanova DI, Avtandlov AG, Vetrile ST. Features of hemodynamics and diastolic function of the right heart of adolescents with a different degree of scoliosis. Kardiologia. 2003:9:64-6.

4. Herrera-Soto JA, Vander Have KL, Barry-Lane P, Woo A. Spinal deformity after combined thoracotomy and sternotomy for congenital heart disease. J Pediatr Orthop. 2006;26(2):211-5
5. Kadhim M, Pizarro C, Holmes L Jr, Rogers KJ, Kallur A, Mackenzie WG. Prevalence of scoliosis in patients with Fontan circulation. Arch Dis Child. 2013;98(3):170-5.

6. Russo L, Aloisi B, lerna A, Centaro A, Negro R, Brancati B. [Scoliosis and mitral valve prolapse. An epidemiological and etiopathogenetic screening (author's transl)]. $G$ Ital Cardiol. 1980;10(8):1001-5.

7. Roclawski M, Pankowski R, Smoczynski A, Ceynowa M, Kloc W, Wasilewski $W$, et al. Secondary scoliosis after thoracotomy in patients with aortic coarctation and patent ductus arteriosus. Stud Health Technol Inform. 2012;176:43-6.

8. Ruiz-Iban MA, Burgos J, Aguado HJ, Diaz-Heredia J, Roger I, Muriel A, et al. Scoliosis after median sternotomy in children with congenital heart disease. Spine (Phila Pa 1976). 2005;30(8):E214-8. 